\title{
CLINICAL CARE OF VESICOURETERAL REFLUX: PREVENTING ADOPTION OF A PROCEDURE-DRIVEN ALGORITHM
}

\author{
Robert A. Mevorach, William C. Hulbert, Cheryl D. Kline and Ronald Rabinowitz.
}

Department of Urology. University of Rochester. Rochester. NY. USA.

\begin{abstract}
Summary.- OBJECTIVES: Although minimally invasive procedures have created a groundswell, supportive of early intervention as an expedient alternative to surveillance, we present a patient-driven model of care that weighs risk and benefit for each individual.
\end{abstract}

METHODS: A practice review was performed for the period 2000-2006. The records of all patients diagnosed by, or referred to, our group (three full-time Pediatric Urologists with a regional service population of 1.7 million) were included in an analysis of vesicoureteral incidence, initial management, and surgical approach.

RESULTS: During the review period, the incidence of newly diagnosed VUR increased at a rate of $4 \%$ per year, with $66 \%$ of these accrued from evaluation of pre-natal hydronephrosis and asymptomatic siblings of known reflux patients. The number of children with VUR and a significant component of DES also increased over time. During this period of higher case volume, surgical intervention failed to increase significantly, but did show a dramatic procedural shift toward minimally invasive techniques for all providers and probable delayed intervention in a substantive number of cases until endoscopic treatment was freely accessible between 2002-2004.

CONCLUSION: Our patient-driven model respects current literature and clinical experience, while acknowledging that our understanding is still currently in evolution. As our knowledge grows, from well-designed prospective study, we adopt new techniques and retire archaic practices. At this point in time, however, we find evidence lacking to support adoption of a procedure-driven algorithm in the care of VUR.

Keywords: Reflux. Ureter. Surgery. Endoscopy. Vesicoureteral reflux.

Resumen.- OBJETIVO: Aunque los procedimientos mínimamente invasivos han creado un clamor popular apoyando la intervención temprana como una alternativa conveniente a la observación, presentamos un modelo de manejo centrado en el paciente, que valora la relación riesgo-beneficio en cada individuo

MÉTODOS: Realizamos una revisión de la práctica clínica en el periodo 2000-2006. Las historias clínicas de todos los pacientes diagnosticados por nuestro grupo o derivados a él (tres urólogos pediátricos con dedicación completa, con una población de referencia de 1,7 millones de habitantes) se incluyeron en un análisis de la incidencia de reflujo vesicoureteral, el manejo inicial y el abordaje quirúrgico.

RESULTADOS: Durante el periodo de revisión, la incidencia de reflujo vesicoureteral de nuevo diagnóstico aumentó con un ritmo del $4 \%$ anual, con un $66 \%$ de los casos provenientes de la evaluación de hidronefrosis prenatales y hermanos asintomáticos de pacientes con reflujo conocido. El número de niños con reflujo vesicoureteral y un componente significativo de síndrome de eliminación disfuncional también ha aumentado con el tiempo durante este período de mayor volumen de 
casos; el número de intervenciones quirúrgicas no ha aumentado significativamente, pero se ha visto un cambio dramático de procedimientos hacia técnicas mínimamente invasivas y un probable retraso de la intervención en un número sustantivo de casos hasta que el tratamiento endoscópico fue libremente accesible entre 2002-2004

CONCLUSIONES: Nuestro modelo dirigido al paciente respeta la literatura actual y la experiencia clínica, y a la vez reconoce que nuestro conocimiento hoy está todavía en evolución. A medida que crece nuestro conocimiento, a partir de estudios prospectivos bien diseñados, adoptamos nuevas técnicas y retiramos las viejas prácticas. En este punto del tiempo, sin embargo, encontramos una falta de evidencia para apoyar la adopción de un algoritmo dirigido por el procedimiento en el cuidado del reflujo vesicoureteral.

Palabras clave: Reflujo. Ureter. Cirugía. Endoscopia. Reflujo vesicoureteral.

\section{INTRODUCTION}

Vesicoureteral reflux (VUR) is an anatomic finding associated with clinical presentation of febrile urinary tract infections in $10-50 \%$ of children $(1,2)$. The recognition of a correlation between the presence of VUR and pyelonephritis, in children, along with a finite incidence of hypertension and renal failure from associated renal scars, served as the driver for aggressive management by both medical and surgical means (3). Unfortunately, this has equated the presence of anatomic VUR with likely renal deterioration when left uncorrected, created a false sense that successful surgery is a panacea for future complications, and permitted the discussion of VUR management to focus primarily on statistically significant outcomes rather than the individual child (2).

Additionally, within the urology literature, there remains an implication that surgical intervention for these cases is inherently more efficacious than pharmacologic management, despite the lack of literature that addresses this particular issue in a prospective manner (4). Finally, the need for a "statistically significant" result to validate a therapeutic approach in the medical literature, ignores clinical experience that bears witness to the often dramatic response of an individual child to a single change in treatment when their current regimen fails them.

Even with attentive stewardship and successful surgical intervention, some children will experience continuing infections that are abated by implementation of medical management. Likewise, some medical failures, in spite of compliance, are reversed by surgical correction of even low-grade VUR. The dilemma for pediatric practitioners, both surgical and medical, is to agree there is an "at risk" group of children for whom reflux management, other than observation, stewardship, and treatment of acute infection, may prove necessary. Further, that within this latter group, $10-20 \%$ of children will continue to experience febrile urinary infection although medically compliant or surgically corrected. As long as these children remain at risk for renal scarring and its potential sequelae, the knowledgeable provider must be willing to seek appropriate treatment and to consider all therapeutic alternatives on an individual basis $(5,6)$.

In order to create a paradigm shift where intervention- pharmacologic, behavioral, and procedural- is performed to result in a maximal number of children without recurrent infections or permanent renal injury, one need not abandon either the literature, or the clinical experience, that has advanced our care to its current level.

Our current practice focuses on the foundation created by a well-informed patient/parent. Our follow-up stresses limited use of invasive imaging with infrequent routine visits, favoring a team concept that includes the primary care physician, rather than exclusive purview. Finally, our care plan emphasizes tailored medical management, patient understanding of long-term issues, and avoidance of a procedurally driven algorithm. This monograph will present an approach to VUR that has evolved from 60 years of combined experience in the care of pediatric patients.

\section{PATIENTS AND METHODS}

A practice review for was performed for the period 2000-2006. The records of all patients diagnosed by, or referred to, our group (three full-time Pediatric Urologists with a regional service population of 1.7 million) were included in an analysis of vesicoureteral incidence, initial management, and surgical approach. The assessment interval chosen includes three 2-year intervals. The first period, 20002002, during which no endoscopic bulking was available as an alternative to open surgery in appropriate cases. The second, 2002-2004, when a limited access to endoscopic injection was offered to 33 children on a research protocol strictly as an option for surgical candidates. The final years, 2004-2006, represented unrestricted access to Hyaluronic Acid/Dextranomer Gel for surgical candidates.

Although initial counseling of children/parents with VUR includes medical and surgical approaches, endoscopic or open surgery is not recommended for initial management. Counseling is provided with emphasis on realistic outcomes of $65-80 \%$ overall spontaneous reflux resolution within 5 years. Our protocol begins with daily antibiotic prophylaxis as initial management and emphasizes attentive clinical surveillance with limited use of imaging unless clinical events create a therapeutic decision point. Surgery was advised for children with recurrent pyelonephritis while compliant with antibiotic prophylaxis; refusal or inability to pursue medical management when faced with repeated febrile urinary infections; failure to resolve reflux after 5 years of follow-up; parental desire, after frank consultation, to pursue an alternative to continued antibiotic use, or observation, particularly in cases of Grade IV-V VUR. All children are assessed by history, physical examination, and imaging for elements of dysfunctional elimination syndrome (DES) and managed as appropriate for age and findings.

An overview of the evaluation and management algorithm illustrates our goal of an individualized approach at the initial visit (Figure 1) and an illustrative case is presented. 


\section{CASE}

LT is an 11 yo girl, who presented to our practice at the age of 8 , with an indwelling Foley catheter for 4 weeks, for evaluation and management of diurnal and nocturnal wetting. On history, she has had recurrent febrile urinary infections since infancy. After a diagnosis of bilateral severe VUR (Grade 3 right, 4 left) by an urologist at the age of 2, she was given prophylactic antibiotics. The renal US reported normal renal size, corticomedullary differentiation, and grade 2 hydronephrosis bilaterally. After being clinically well for 9 months, a repeat VCUG and US were performed revealing normal renal growth, but otherwise without changes. She was scheduled for ureteral reimplantation bilaterally, and told that there were no viable alternatives. She was lost to follow-up at this point and her history reveals repeated urgent care and emergency room visits for febrile urinary infections, the most recent 4 weeks prior to our first meeting.

On further review, she has bowel and bladder incontinence for 2 years and a review of old diagnostic images reveal significant constipation, but no bladder wall thickening in infancy. Her clinical chemistries are creatinine $4.7 \mathrm{mg} / \mathrm{dl}, \mathrm{BUN} 52$, without acidosis or hyperkalemia. A cystometrogram revealed uninhibited detrusor contractions and a non-compliant bladder with filling pressure of $48 \mathrm{~cm}$ $\mathrm{H} 2 \mathrm{O}$ at $67 \mathrm{ccs}$. She was begun on a regimen of clean intermittent catheterization, indwelling catheter overnight, anticholinergic and antibiotic medications, and an aggressive bowel regimen. Over the next 9 months, after constant monitoring and therapeutic adjustments by nephrology (pending dialysis) and pediatric urology she became continent of stool, urinary accidents only when catheterization was not performed by 3.5 hours, and was infection free. Her creatinine remained stable at $4.4-4.8 \mathrm{mg} / \mathrm{dl}$.

Over the next 9 months, she was seen monthly by the nephrology service, and suffered 4 episodes of pyelonephritis all coincident with cessation of her overnight bladder drainage by a non-urologic provider. At this juncture the patient was re-referred for our input. The ensuing 4 months found her well on her prescribed bladder management, and she underwent renal transplantation without additional pediatric urology input regarding pre- or intra-operative care. After 2 episodes of clinical pyelonephritis without localization of infection to either transplant or native kidney by appropriate diagnostic imaging, pediatric urology was made aware of her transplant and current clinical status. A repeat VCUG was obtained (Figure 3) and a recommendation made for trilateral endoscopic treatment. She is currently 8 months post-injection therapy and has been infection free, clinically well, with a creatinine of $1.0 \mathrm{mg} / \mathrm{dl}$.

\section{RESULTS}

During the review period, the incidence of newly diagnosed VUR increased at a rate of $4 \%$ per year, with $66 \%$ of these accrued from evaluation of pre-natal hydrone-

$\begin{aligned} & \text { Grade I (girls) } \\ & \text { Grade I-II (boys) }\end{aligned}$
$\begin{aligned} & \text { Recommend Antibiotics } \\ & \text { For 1 year. Repeat US. }\end{aligned}$
Observe.
(VCUG Optional)


phrosis and asymptomatic siblings of known reflux patients. The number of children with VUR and a significant component of DES also increased over time (Table I). During this period of higher case volume, surgical intervention failed to increase significantly, but did show a dramatic procedural shift toward minimally invasive techniques for all providers and probable delayed intervention in a substantive number of cases until endoscopic treatment was freely accessible between 2002-2004 (Table II).

Nine children underwent surgical management after breakthrough pyelonephritis while on prophylaxis 12 open, 7 endoscopic) in 2006 and are clinically well postoperatively. Eleven children, during the same period, are openly non-compliant with medical management, without clinical sequelae. Only one child has undergone open surgery for failed endoscopic treatment.

At the current time, $82 \%$ of children treated by a single endoscopic bulking procedure are free of reflux on VCUG performed 3 months post-operatively. These cases include Grade V, bilateral, and duplex systems without deterioration of results. Nine of 10 treatment failures opt for repeat injection, and $80 \%$ are cured by the second procedure. Over $75 \%$ of children who chose observation after failed first injection have been clinically well on observation alone. Recurrent pyelonephritis after successful injection occurred in $0.8 \%$ of children and was related to recurrence
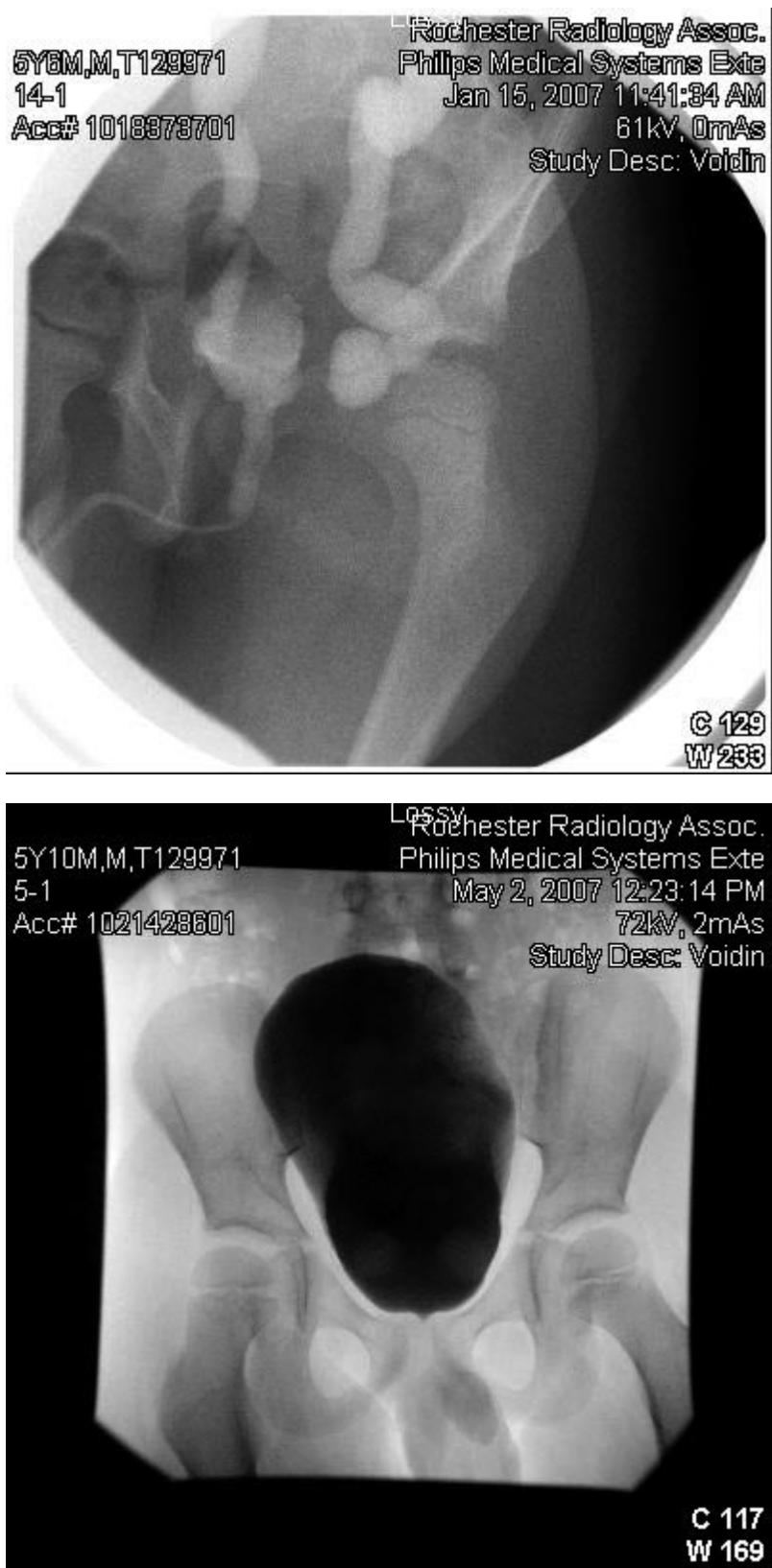
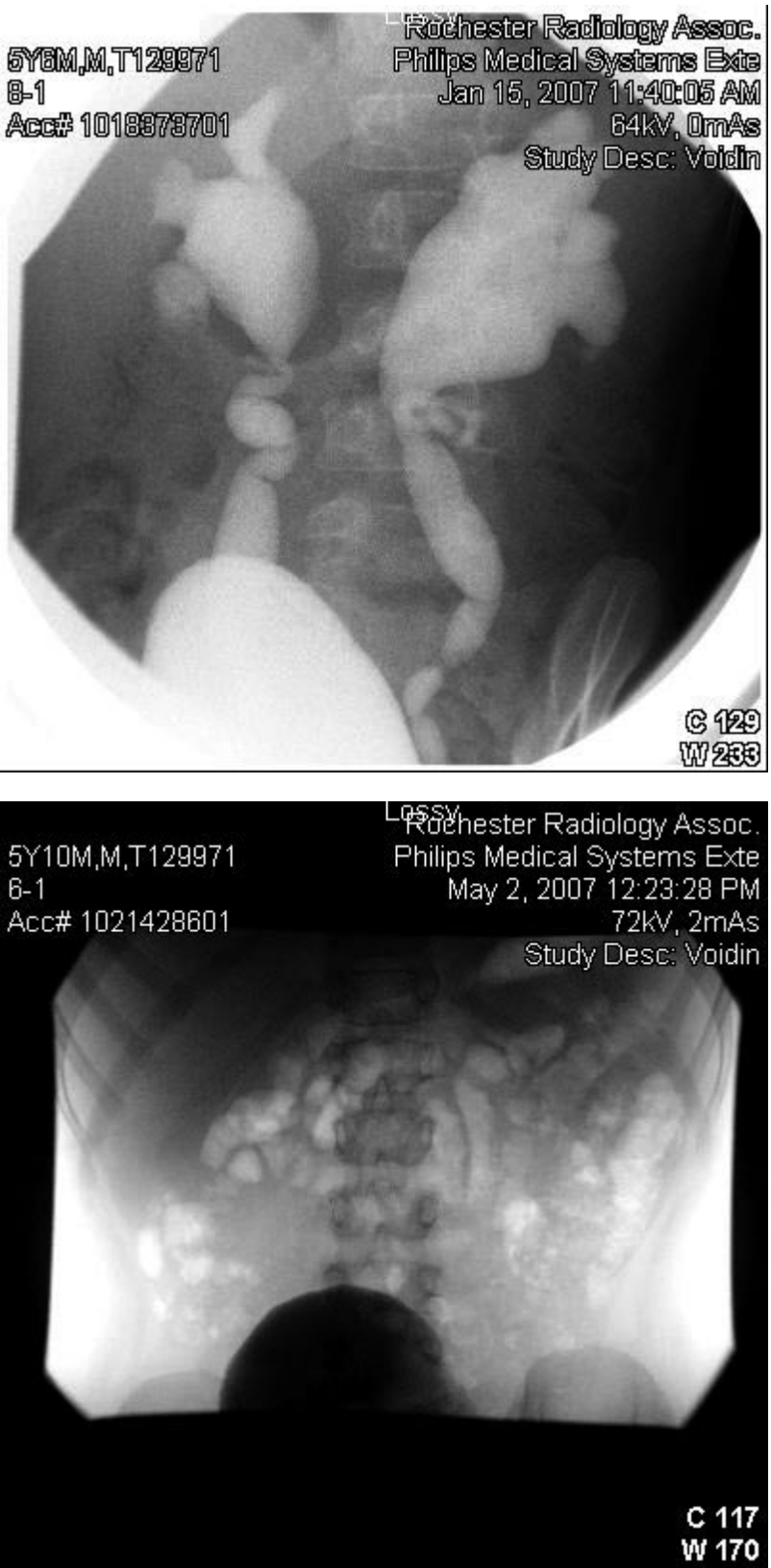

FIGURE 2. Representative images of preoperative (a) and post-injection (b) VCUG in a four year old boy. 
TABLE I. NEW DIAGNOSIS OF VUR.

\begin{tabular}{|c|c|c|c|c|}
\hline Practice Period & Unilateral Reflux & Bilateral Reflux & Associated DES & Practice Totals \\
\hline $2000-2002$ & 116 & 152 & 55 & 323 \\
\hline $2002-2004$ & 123 & 170 & 62 & 355 \\
\hline $2004-2006$ & 131 & 177 & 89 & 397 \\
\hline
\end{tabular}

of significant DES in the majority of cases. Compliance with antibiotic prophylaxis exceeds $90 \%$ by parent report and is likely bolstered by allowing flexibility for parents to choose treatment of clinical events only, when they are concerned by continuous exposure.

Images of an endoscopic treatment are shown in Figure 2. This demonstrates the degree of reflux and latitude of ureteral anatomy that we consider acceptable for management by injection.

\section{DISCUSSION}

Our practice has always been driven by an intention to use our experience and an understanding of the literature to treat each child as an individual. Our experience teaches us that the majority of infants will resolve their VUR, during 5 years of observation, with infrequent clinical issues while on prophylactic antibiotics. Thirty years ago, Lenaghan and Stephens expressed the same view, and further advised that infection, not anatomic reflux, was the clinical risk factor (3). Even when an older group of children are included, from two separate tertiary centers, one may expect up to $65 \%$ resolution over the same 5 years of observation $(7,8)$.
Medical management with antibiotic prophylaxis, while empirically sound, has had its validity questioned in the literature (4). We recommend antibiotic prophylaxis during the initial observation period of $4-5$ years after diagnosis and feel it reduces the incidence of clinical infection. Statistical support for this recommendation is lacking in the literature, but varied authors have assessed a benefit to prophylactic antimicrobials, in sequential decades over the past 30 years $(3,9,10)$. A parent who chooses to avoid continuous antimicrobials, although informed that our experience suggests utility, is counseled regarding the lack of evidence-based risk or benefit to their choice, and likewise for our recommendation.

We do not offer surgery as the only alternative, at this juncture, as long as surveillance for clinical signs of infection is deemed reliable and combined with annual ultrasound evaluation for renal growth. Our goal is to maintain patient contact so any deviation from clinical goals is readily reported and immediately addressed. If intervention, medical or surgical, is inflexible to the concerns raised by parents and pediatricians, we will lose ownership of these children to less experienced providers. By focusing attention on the child's clinical status and renal preservation by "all means as necessity dictates", a dialogue is maintained. As illustrated by the case of LT, without this flexibility, parents

TABLE II. ANNUAL TREATMENT OF VUR.

\begin{tabular}{|c|c|c|c|c|}
\hline Practice Period & Reimplant-Unilateral & Reimplant- Bilateral & Endoscopic Injection & Totals \\
\hline $2000-2002$ & 31 & 68 & 0 & 99 \\
\hline $2002-2004$ & 13 & 24 & 33 & 70 \\
\hline $2004-2006$ & 8 & 18 & 113 & 139 \\
\hline
\end{tabular}


have retreated from care and we see their children, often after years of unheeded warning signs, for pre-transplant assessment (11).

The cost of health care, on a population basis, is unaffected by the therapeutic choice for the management of VUR, simply because of "economies of scale" (12). Our recommendation for endoscopic injection in surgical candidates, although open surgery is thoroughly outlined and discussed, has been based on ease of recovery, excellent patient outcome, and parental preference. In our practice, follow-up VCUG is recommended after both open and endoscopic surgery, so this does not influence parental choice. Additionally, this technique is supported by recent cost-effectiveness modeling when compared to open surgery $(13,14)$. Our results for both resolution rates and subsequent febrile urinary infections compare favorably to the literature, including a recent meta-analysis $(15,16$, 17). Our operative volume has increased for 2004-2006, but is likely the result of delayed management of surgical candidates (2002-2004) until access was achieved to an FDA-approved substance for injection. With deference to
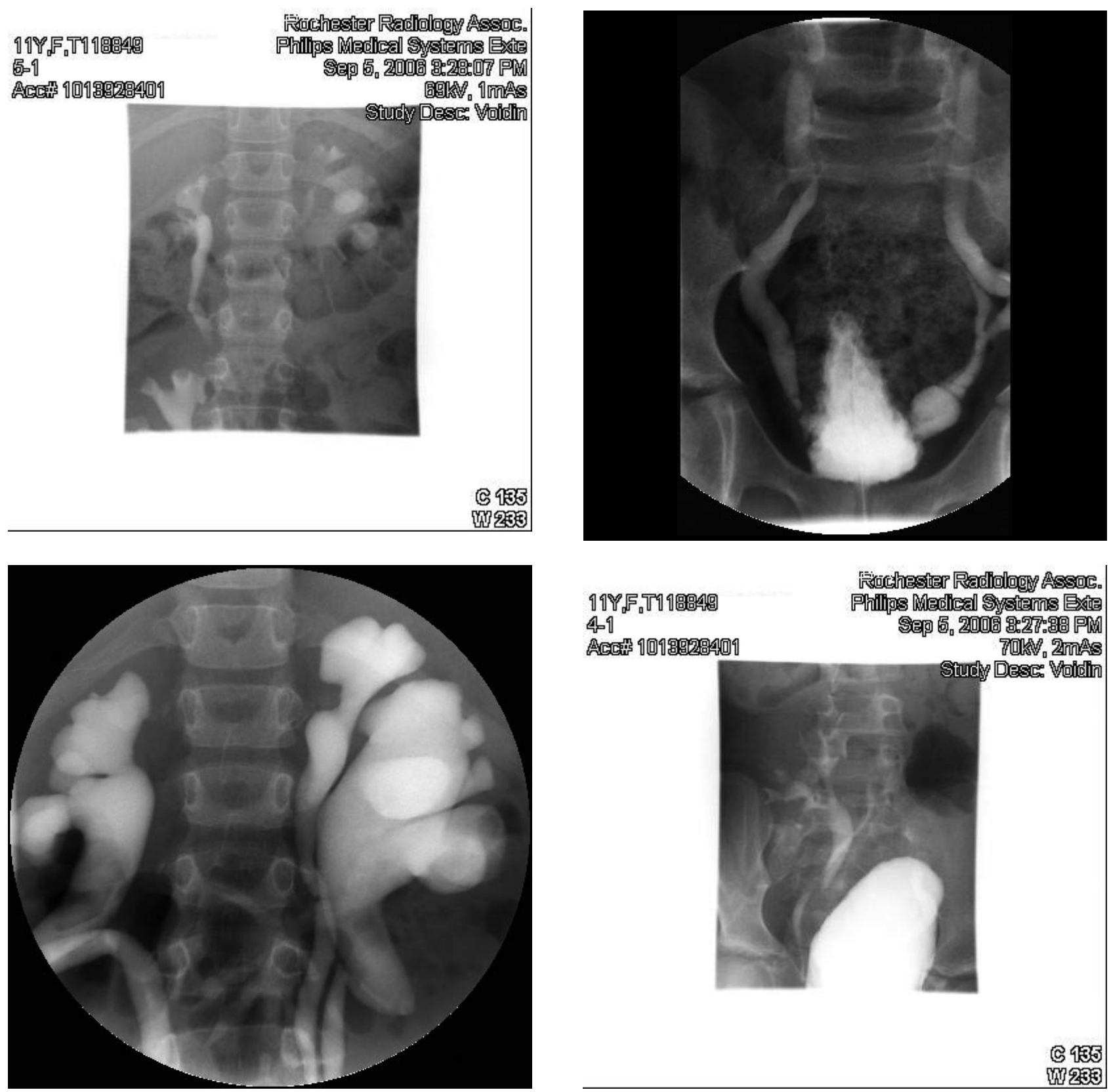

FIGURE 3. Pre-treatment (a) and pre-transplant (b) images demonstrating severe VUR to native kidneys (a, b) and transplant kidney (b). Improved bladder capacity and reduced trabeculation is noted in (b) compared to "Christmas Tree" appearance of (a). 
Lendvay, et al, we do not perceive an increase tendency toward early intervention, but rather a centralization of VUR cases to pediatric sub-specialists who offer endoscopic injection as an alternative to open surgery (18).

The growing trend toward early injection of VUR is often supported under the guise of parental preference (19). Apparent in our experience, and supported by Ogan, et al, is the ease with which one can alter this preference by simply foregoing an annual voiding cystourethrogram (VCUG). 20 Our current approach sets at least 2 year intervals between VCUGs in medically managed patients. A respect for parental input requires a respect for the validity of the information upon which they base their decisions. Although endoscopic injection is empirically safe and clinically effective, $12 \%$ relapse rates coupled with persistent infections (9-27\%) clearly define a need for both long-term awareness, and short-term risk-benefit discussion $(21,22)$. Parents must choose any intervention with an appreciation of the latter information, and with further open discussion of pregnancy and long term impact of VUR in all girls $(22,23)$.

Minimally invasive surgery requires anesthesia, and even biocompatible materials incite inflammatory reactions in certain cases (24). These represent a finite risk, but intervention is never without potential complication. In our solitary open surgery after failed injection, we encountered severe fibrosis and a foreign-body giant cell reaction that raises the possibility of delayed obstruction of the ureter, as reported by Routh et al. (Abstract American Academy of Pediatric, 2006 Atlanta) Parents and patients must view endoscopic surgery as a part of a long-term clinical relationship, not as a convenient solution to VUR and its sequelae. Some patients believe that the presence of minimal renal scarring, on initial evaluation, is an absolute indication for early surgery unless they choose to be "negligent". Evidence for minor past renal injury predicting poor future clinical course is lacking, and therefore emphasizing this finding creates an undue sense of urgency.

Additionally neither VUR correction by surgical means, nor successful antibiotic prophylaxis, will necessarily prevent subsequent deterioration in the case of severe renal scarring $(25,26)$. Preventing all ongoing renal injury in children with VUR may be outside the capability of our available management, but parents can expect make decisions with current knowledge without the effect of hyperbole, or unsubstantiated imperatives.

\section{CONCLUSION}

We pediatric urologists must continue to pursue maximal outcomes, minimal invasions, and the best quality of life for our patients with VUR. Our patient-driven model respects current literature and clinical experience, while acknowledging that our understanding is still currently in evolution. As our knowledge grows, from well-designed prospective study, we adopt new techniques and retire archaic practices. At this point in time, however, we find evidence lacking to support adoption of a procedure-driven algorithm in the care of VUR.

\section{REFERENCES AND RECOMENDED READINGS (*of special interest, ${ }^{* *}$ of outstanding interest)}

*1. OLBING, H.; TAMMINEN-MOBIUS, T.; JODAL, U. y cols.: "Management of primary vesico-ureteric reflux in children-operation ineffective in preventing progress of renal damage (Infection 22 [1994] S4-S7)". Infection, 23: 248, 1995.

2. HOBERMAN, A.; CHARRON, M.; HICKEY, R.W. y cols.: "Imaging studies after a first febrile urinary tract infection in young children". N. Engl. J. Med., 348: 195, 2003.

3. LENAGHAN, D.; WHITAKER, J.G.; JENSEN, F. y cols.: "The natural history of reflux and long-term effects of reflux on the kidney". J. Urol., 115: 728, 1976.

**4. WHEELER, D.M.; VIMALACHANDRA, D.; HODSON, E. y cols.: "Interventions for primary vesicoureteric reflux". Cochrane Database Syst. Rev., 3: 1532, 2004.

5. KOGAN, B.A.: "Natural history of neonatal reflux associated with prenatal hydronephrosis: Long-term results of a prospective study". Int. Braz. J. Urol., 29: 188, 2003.

6. ELDER, J.S.; PETERS, C.A.; ARANT, B.S. Jr. y cols.: "Pediatric Vesicoureteral Reflux Guidelines Panel summary report on the management of primary vesicoureteral reflux in children”. J. Urol., 157: 1846, 1997.

7. SCHWAB, C.W. Jr.; WU, H.Y.; SELMAN, H. y cols.: "Spontaneous resolution of vesicoureteral reflux: A 15year perspective". J. Urol., 168: 2594, 2002.

8. CONNOLLY, L.P.; ZURAKOWSKI, D.; CONNOLLY, S.A. y cols .: "Natural history of vesicoureteral reflux in girls after age 5 years". J. Urol., 166: 2359, 2001.

**9. SZLYK, G.R.; WILLIAMS, S.B.; MAJD, M. y cols.: "Incidence of new renal parenchymal inflammatory changes following breakthrough urinary tract infection in patients with vesicoureteral reflux treated with antibiotic prophylaxis: Evaluation by 99MTechnetium dimercapto-succinic acid renal scan”. J. Urol., 170: 1566, 2003.

**10. JODAL, U.; SMELLIE, J.M.; LAX, H. y cols.: "Tenyear results of randomized treatment of children with severe vesicoureteral reflux. Final report of the International Reflux Study in Children". Pediatr. Nephrol., 21: 785, 2006.

11. HSIEH, M.H.; SWANA, H.S.; BASKIN, L.S. y cols.: "Cost-utility analysis of treatment algorithms for moderate grade vesicoureteral reflux using Markov models". J. Urol., 177: 703, 2007.

12. BENOIT, R.M.; PEELE, P.B.; CANNON, G.M. Jr. y cols.: "The cost-effectiveness of dextranomer/hyaluronic acid copolymer for the management of vesicoureteral reflux. 2. Reflux correction at the time of diagnosis as a substitute for traditional management". J. Urol., 176: 2649, 2006.

*13. BENOIT, R.M.; PEELE, P.B.; DOCIMO, S.G.: "The cost-effectiveness of dextranomer/hyaluronic acid copolymer for the management of vesicoureteral reflux. 1: substitution for surgical management". J. Urol., 176: 1588, 2006. 
**14. ELDER, J.S.; DIAZ, M.; CALDAMONE, A.A. y cols.: "Endoscopic therapy for vesicoureteral reflux: a metaanalysis. I. Reflux resolution and urinary tract infection". J. Urol., 175: 716, 2006.

15. KIRSCH, A.J.; PEREZ-BRAYFIELD, M.R.; SCHERZ, H.C.: "Minimally invasive treatment of vesicoureteral reflux with endoscopic injection of dextranomer/hyaluronic acid copolymer: The Children's Hospitals of Atlanta experience". J. Urol., 170: 211, 2003.

16. YU, R.N.; ROTH, D.R.: "Treatment of vesicoureteral reflux using endoscopic injection of nonanimal stabilized hyaluronic acid/dextranomer gel: Initial experience in pediatric patients by a single surgeon". Pediatrics, 118: 698, 2006.

17. LENDVAY, T.S.; SORENSEN, M.; COWAN, C.A. y cols.: "The evolution of vesicoureteral reflux management in the era of dextranomer/hyaluronic acid copolymer: A pediatric health information system database study". J. Urol., 176: 1864, 2006.

18. CAPOZZA, N.; LAIS, A.; MATARAZZO, E. y cols.: "Treatment of vesico-ureteric reflux: a new algorithm based on parental preference". BJU Int., 92: 285, 2003.

19. OGAN, K.; POHL, H.G.; CARLSON, D. y cols.: "Parental preferences in the management of vesicoureteral reflux". J. Urol., 166: 240, 2001.

20. STENBERG, A.; HENSLE, T.W.; LACKGREN, G.: "Vesicoureteral reflux: A new treatment algorithm".
Curr. Urol. Rep., 3: 107, 2002.

21. MOR, Y.; LEIBOVITCH, I.; ZALTS, R. y cols .: "Analysis of the long-term outcome of surgically corrected vesico-ureteric reflux". BJU Int., 92: 97, 2003.

22. MANSFIELD, J.T.; SNOW, B.W.; CARTWRIGHT, P.C. y cols.: "Complications of pregnancy in women after childhood reimplantation for vesicoureteral reflux: An update with 25 years of followup". J. Urol., 154: 787, 1995.

*23. VANDERSTEEN, D.R.; ROUTH, J.C.; KIRSCH, A.J. y cols.: "Postoperative ureteral obstruction after subureteral injection of dextranomer/hyaluronic Acid copolymer". J. Urol., 176: 1593, 2006.

**24. OLBING, H.; SMELLIE, J.M.; JODAL, U. y cols.: "New renal scars in children with severe VUR: a 10year study of randomized treatment". Pediatr. Nephrol., 18: 1128, 2003.

25. WINBERG, J.; BOLLGREN, I.; KALLENIUS, G. y cols.: "Clinical pyelonephritis and focal renal scarring. A selected review of pathogenesis, prevention, and prognosis”. Pediatr. Clin. North Am., 29: 801, 1982. LACKGREN, G.; SKOLDENBERG, E.; STEN-

26. BERG, A.: "Endoscopic treatment with stabilized nonanimal hyaluronic acid/dextranomer gel is effective in vesicoureteral reflux associated with bladder dysfunction". J. Urol., 177: 1124, 2007. 